\title{
Evaluasi Usability User Interface dan User Experience Aplikasi SAKERNAS PANEL 2018 Badan Pusat Statistik Kota Tangerang Selatan
}

\author{
Ashifa Ayuningtias ${ }^{1}$, Muhammad Qomarul Huda²
}

\begin{abstract}
Badan Pusat Statistik merupakan lembaga non kementrian dimana lembaga ini bertanggung jawab langsung kepada presiden. Sebelumnya, BPS merupakan Biro Pusat Statistik, yang dibentuk berdasarkan UU Nomor 6 Tahun 1960 tentang Sensus dan UU Nomer 7 Tahun 1960 tentang Statistik. Setiap sistem harus memiliki kualitas yang baik agar mudah digunakan oleh pengguna. Untuk menguji kualitas sistem tersebut maka dilakukan evaluasi sistem dengan menggunakan metode pengujian usability dengan mengobservasi pengguna dengan metode observasi, dilanjutkan dengan metode dan kuesioner Nielsen's Attributtes Of Usability (NAU). Berdasarkan hasil penelitian yang dilakukan dengan metode observasi Aplikasi SAKERNAS berada pada tingkat ke-3 dari 5 skala atau Cukup, lalu dengan kuesioner NAU dapat disimpulkan bahwa Aplikasi SAKERNAS Badan Pusat Statistik CUKUP dalam memenuhi kelima kategori usability menurut Nielsen Model.
\end{abstract}

Keywords-Usability, Evaluasi, Nielsen's Attributtes Of Usability, Kualitas Sistem, Sistem, Kuis.

$\mathrm{P}$

\section{Pendahuluan} memanfaatkan teknologi informasi dan komunikasi dalam bidang e-government yang terintegrasi, mulai dari tingkat pemerintah daerah hingga ke pusat [1]. Kebijakan pemerintah tersebut dituangkan dalam Instruksi Presiden No.3 Tahun 2003 tentang Kebijakan dan Strategis Nasional Pengembangan e-Government dan Keputusan Mentri Komunikasi dan informasi No 57 Tahun 2003 tentang Panduan Penyusunan Rencana Induk Pengembangan e-Government.

Bersumber pada Instruksi Presiden dan Keputusan Mentri Komunikasi dan informasi diatas maka Badan Pusat Statistik (BPS) yang beralamat di Jalan Dr. Sutomo 6-8 Jakarta 10710 Indonesia, membuat aplikasi SAKERNAS dengan tujuan untuk memudahkan Survey Ketenagakerjaan Nasional terkait kegiatan statistik di Indonesia[2].

Received: 28 April 2019 ; Revised: 5 September 2019 ; Accepted: 10 September 2019

http://journal.uinjkt.ac.id/index.php/aism
Badan Pusat Statistik menyediakan sebuah system informasi secara online yaitu sistem informasi Survey Ketenagakerjaan Nasional (SAKERNAS PANEL) 2018 yang akan digunakan Badan Pusat Statistik tingkat provinsi dan kota untuk entry data hasil survey lapangan untuk dikumpulkan dan diolah oleh Badan Pusat Statistik Pusat [3, 4]. Aplikasi yang disediakan ini, sangat penting dan harus diperhatikan dengan baik dari berbagai aspek, dikarenakan aplikasi SAKERNAS PANEL 2018 akan digunakan oleh semua Badan Pusat Statistik provinsi dan kota di seluruh Indonesia[3].

\section{KAJIAN PENELITIAN}

Usability adalah sejauh mana suatu produk dapat digunakan oleh pengguna tertentu untuk mencapai target yang ditetapkan dengan efektivitas, efesiensi dan mencapai kepuasan penggunaan dalam konteks tertentu [5] . Konteks penggunaan terdiri dari pengguna, tugas, peralatan (hardware, software dan material). Berdasarkan definisi tersebut usability diukur berdasarkan komponen :

A. Kemudahan (learnability) dapat dinilai dari kecepatan para pengguna memahami dan mahir dalam menggunakan sistem serta kecepatan pengguna menjalankan fungsi tertentu untuk mendapatkan yang mereka inginkan [6].

B. Efisiensi (efficiency) merupakan sumber daya yang dikeluarkan dengan tujuan pengguna dapat mencapai ketepatan dan kelengkapan [7].

C. Mudah diingat (memorability) dapat dinilai dari bagaimana para pengguna mampu mengingat pengetahuannya dalam jangka waktu yang cukup, dimana hal ini dapat dinilai dari peletakkan menu yang selalu tetap[8].

D. Kesalahan dan keamanan (errors) merupakan penilaian dari seberapa banyak kesalahan apa saja yang mungkin terjadi oleh pengguna,contoh kesalahan yang dibuat pengguna ialah ketidaksesuaian apa yang pengguna pikirkan dengan apa yang sebenarnya disajikan oleh sistem [9].

A. Ayuningtiyas, Japanese Marketing Department Sompo Insurance Indonesia, Indonesia (e-mail: ashifayu@gmail.com).

M.Q. Huda, Prodi Sistem Informasi, UIN Syarif Hidayatullah Jakarta, Indonesia (e-mail: mqomarul@uinjkt.ac.id ). 
E. Kepuasan (satisfaction) dapat didefinisikan dengan kurang nyamannya para pengguna dan sikap positif dari para pengguna akan penggunaan produk atau ukuran subjektif sebagaimana perasaan pengguna terhadap penggunaan sistem [10].

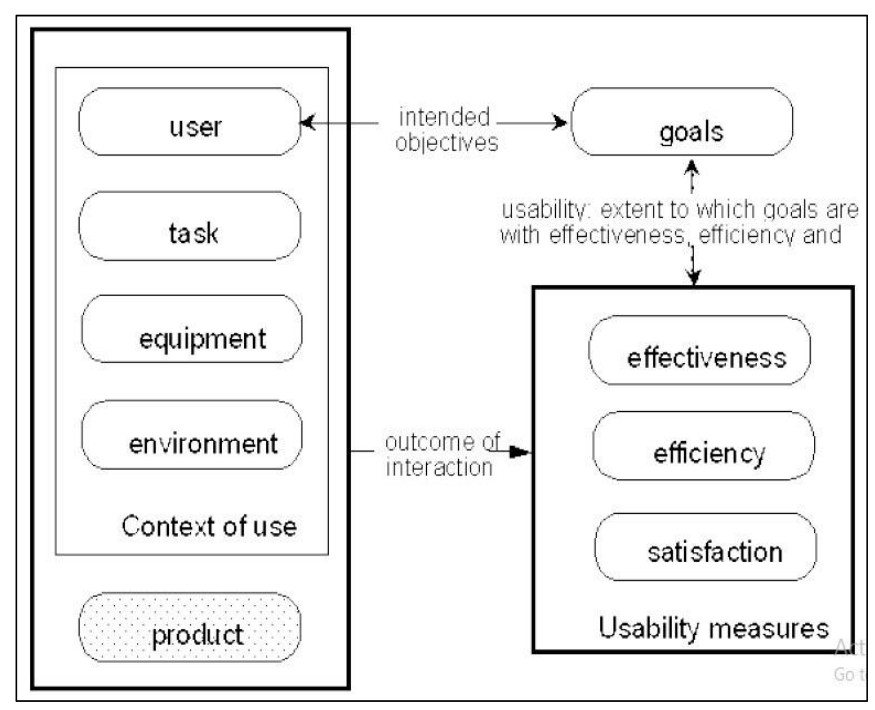

Gambar 1. Kerangka Kerja ISO 9241-11

Kerangka kerja pada gambar 1. ini merupakan gambaran dari setiap komponen usability dan hubungannya. Untuk mengukur usability diperlukan utnuk mengidentifikasi tujuan serta melakukan definisi terhadap kriteria seperti effectiveness, efficiency, dan satisfaction kedalam konteks penggunaan, kemudian membuat ukuran beserta variabelnya.

Nielsen mendefinisikan bahwa usability adalah suatu tolak ukur sebuah kualitas yang mengkaji serta mengkur seberapa mudah tampilan (interface) digunakan oleh pengguna. Menurutnya, ada lima kategori utama dari usability, diantaranya adalah Learnability, Efficiency, Memorability, Errors, Satisfaction [11].

Kualitas merupakan suatu kondisi dinamis yang berhubungan dengan produk, jasa, manusia, proses, dan lingkungan yang memenuhi atau melebihi harapan. Kualitas ini meliputi berbagai hal yang terkait dalam penggunaan sistem. DeLone dan Mclean mengemukakan beberapa dimensi yang terkait dengan kualitas sistem, yaitu:

A. Kualitas Sistem (System Quality), dimensi ini mengukur beberapa karakteristik yang diinginkan pada suatu sistem, contohnya usability, availability, reliability, adaptability adalah contoh-contoh kualitas yang dinilai oleh pengguna sistem [12].

B. Kualitas Informasi (Information Quality), dimensi ini membahas masalah konten sistem. Sistem selayaknya bersifat personal, lengkap, relevan, mudah dipahami, dan aman [13].

C. Kualitas Layanan (Service Quality), keseluruhan dukungan yang disampaikan oleh penyedia layanan, berlaku terlepas dari apakah dukungan ini disampaikan oleh departemen IS, atau unit organisasi baru [14].

http://journal.uinjkt.ac.id/index.php/aism
III. HASIL DAN PEMBAHASAN

TAHAP AWAL TAHAP ANALISIS TAHAP AKHIR

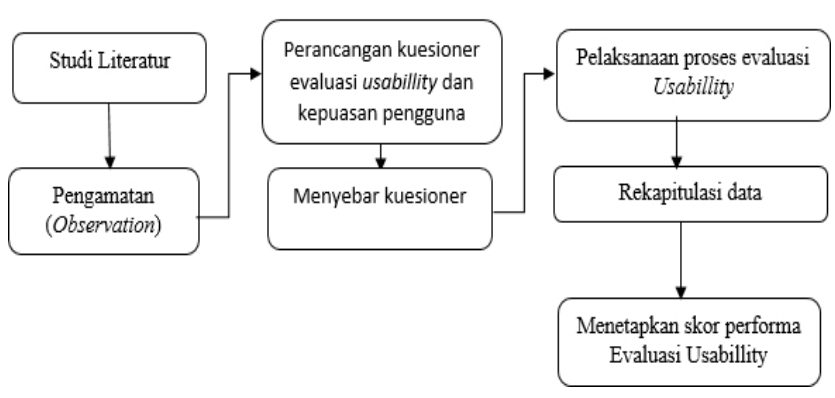

Gambar 2. Diagram Alur Penelitian

Diagram alur penelitian dapat dilihat pada gambar 2 . Metode Pengumpulan data secara umum diartikan sebagai proses, cara, atau prosedur yang digunakan untuk memecahkan suatu masalah. Metode yang digunakan untuk mengumpulkan data dalam penelitian ini adalah sebagai berikut

A. Studi Literatur

Pada proses ini kegiatan yang dilakukan diantaranya adalah mengkaji dan memperdalam pemahaman terkait dasar-dasar mengenai konsep usability serta metode- metode yang cocok untuk digunakan dalam melakukan pengujian terhadap usability suatu sistem. Sumber literature dapat berasal dari buku, jurnal internasional, jurnal nasional, website, dan sebagainya.

B. Studi Pustaka,

Metode pengumpulan data yang diarahkan kepada pencarian data dan informasi melalui dokumen-dokumen.

C. Studi Lapangan

Dimana studi lapangan disini merupakan proses pengumpulan data dari perusahaan tertentu dengan mencatat data - data yang diperlukan dari dokumen perusahaan tersebut.

1) Pengamatan/Observation

Pengamatan/observation yang dilakukan dengan cara mengunjungi langsung kantor Badan Pusat Statistik Tangerang Selatan yang beralamatkan di Jl. Raya Pahlawan Seribu - Puspiptek Kel. Kademangan Kec. Setu Tangerang Selatan, Banten, Indonesia.

2) Wawancara

Adalah salah satu pengumpulan data yang dilakukan dengan jalan wawancara dan berdiskusi langsung dengan pengguna sistem SAKERNAS PANEL Badan Pusat Statistik dan lainlain yang berhubungan dengan objek yang diteliti.

3) Kuesioner

Perancangan Kuesioner Evaluasi Usability dan Kepuasan Pengguna Kuesioner evaluasi usability yang dikembangkan adalah seperangkat kuesioner yang terdiri dari, formulir data diri responden dan kuesioner evaluasi usability, serta formulir pendapat responden mengenai situs web yang dievaluasi yang didasarkan pada penilaian Questionnaire for User Interface Satisfaction (QUIS) versi 5.0 yang diterbitkan oleh University of Maryland. Formulir QUIS 
versi 5.0 berisi 14 pertanyaan yang telah disesuailkan dengan menggunakan skala Likert $0-9$, dan digunakan juga kuesionerNAU (Nelsen Attributtes Of Usability) yang didalamnya terdapat 5 aspek usability seperti learnability, efficiency, memorability, errors, dan satisfaction.

\section{HASIL DAN PEMBAHASAN}

Analisa Kuesioner Nielsen Attributtes of Usability (NAU) adalah metode yang digunakan untuk pengujian kualitatif terkait usability suatu sistem dengan menggunakan media kuesioner. Dimana pengujian ini dilakukan dengan mengajukan beberapa pertanyaan yang berkaitan dengan 5 kategori usability seperti Learnability, Efficiency, Memorability, Error, dan Satisfaction.

\section{A. Learnability}

Tabel 1.

Analisis Jawaban Learnability

\begin{tabular}{lccccc}
\hline \hline & 1 & 2 & 3 & 4 & 5 \\
\hline Q1 & $0 \%$ & $13,3 \%$ & $26,7 \%$ & $48,9 \%$ & $11,1 \%$ \\
Q2 & $4,4 \%$ & $26,7 \%$ & $22,2 \%$ & $31,1 \%$ & $15,6 \%$ \\
Q3 & $0 \%$ & $8,9 \%$ & $31,1 \%$ & $48,9 \%$ & $11,1 \%$ \\
Q4 & $2,2 \%$ & $15,6 \%$ & $33,3 \%$ & $44,4 \%$ & $4,4 \%$ \\
Q5 & $6,7 \%$ & $8,9 \%$ & $31,1 \%$ & $37,8 \%$ & $15,6 \%$ \\
AVG & $2,66 \%$ & $14,7 \%$ & $28,88 \%$ & $42,22 \%$ & $11,56 \%$ \\
\hline \hline
\end{tabular}

Dapat dilihat pada tabel 1 . hanya $2,66 \%$ dari responden memilih pilihan $1,14,7 \%$ dari responden pemilih pilihan 2 , sedangkan sekitar $28,88 \%$ dari responden memilih pilihan CUKUP dengan pilihan nomor 3, dan $42,22 \%$ untuk pilihan 4 serta $11,56 \%$ untuk pilihan 5 .

\begin{tabular}{|l|l|}
\hline \multicolumn{1}{|c|}{ Indikator } & \multicolumn{1}{|c|}{ Hasil } \\
\hline Easy to Understand & $\begin{array}{l}\text { CUKUP dalam memahami Aplikasi RAKERNAS } \\
\text { Badan Pusat Statistik dengan rata-rata jawaban } \\
\text { yaitu 3,42 }\end{array}$ \\
\hline $\begin{array}{l}\text { Easy to Look for } \\
\text { Spesific Information }\end{array}$ & $\begin{array}{l}\text { CUKUP dengan pernyataan bahwa mereka mudah } \\
\text { dalam mendapatkan informasi tertentu pada } \\
\text { Aplikasi RAKERNAS Badan Pusat Statistik ini } \\
\text { dengan rata-rata jawaban 3,47 }\end{array}$ \\
\hline $\begin{array}{l}\text { Navigational to Identify } \\
\text { Mechanism }\end{array}$ & $\begin{array}{l}\text { CUKUP dengan pernyataan bahwa mudah untuk } \\
\text { memahami mekanisme navigasi yang ditawarkan } \\
\text { pada Aplikasi RAKERNAS Badan Pusat Statistik } \\
\text { dengan rata-rata jawaban 3,46 }\end{array}$ \\
\hline
\end{tabular}

Gambar 3. Analisis Indikator Learnability

Hasil pada tabel tersebut menunjukkan Aplikasi SAKERNAS Badan Pusat Statistik CUKUP memenuhi aspek learnability, hal ini dibuktikan dengan rata-rata secara keseluruhan mencapai 3,45.

\section{B. Efficiency}

Jawaban terbanyak pada table 2. yang dipilih oleh

http://journal.uinjkt.ac.id/index.php/aism responden adalah pilihan jawaban 3 dan 4 dengan total jawaban hingga 76,29\%, sedangkan untuk pilihan jawaban 1 dan 2 hanya dipilih oleh total $17,03 \%$ dari jumlah responden, dan sisanya sebesar 6,5\% memilih jawaban 5 .

Tabel 2.

Analisis Jawaban Efficiency

\begin{tabular}{lccccc}
\hline \hline & 1 & 2 & 3 & 4 & 5 \\
\hline Q6 & $4,4 \%$ & $15,6 \%$ & $28,9 \%$ & $37,8 \%$ & $13,3 \%$ \\
Q7 & $2,2 \%$ & $11,1 \%$ & $37,8 \%$ & $44,4 \%$ & $4,4 \%$ \\
Q8 & $2,2 \%$ & $15,6 \%$ & $37,8 \%$ & $42,2 \%$ & $2, \%$ \\
AVG & $2,93 \%$ & $14,1 \%$ & $34,83 \%$ & $41,46 \%$ & $6,5 \%$
\end{tabular}

\begin{tabular}{|c|c|}
\hline Indikator & Hasil \\
\hline Easy to Reach Quickly & $\begin{array}{l}\text { Sikap responden CUKUP dalam menemukan atau } \\
\text { mencapai informasi yang dicari pada Aplikasi } \\
\text { RAKERNAS Badan Pusat Statistik ini dengan rata- } \\
\text { rata jawaban } \mathbf{3 , 3 8}\end{array}$ \\
\hline Easy to Navigate & $\begin{array}{l}\text { Sikap responden CUKUP dengan pernyataan } \\
\text { bahwa mereka mudah dalam mendapatkan } \\
\text { informasi tertentu pada Aplikasi RAKERNAS } \\
\text { Badan Pusat Statistik ini dengan rata-rata jawaban } \\
\mathbf{3 , 2 6}\end{array}$ \\
\hline
\end{tabular}

Gambar 4. Analisis Indikator Efficiency

Secara keseluruhan, Gambar 4. Memeprlihatkan responden menyatakan CUKUP bahwa Aplikasi SAKERNAS Badan Pusat Statistik telah memenuhi aspek efficiency dengan ratarata jawaban 3,32.

\section{Memorability}

Tabel 3.

Analisis Jawaban Memorability

\begin{tabular}{lccccc}
\hline \hline & 1 & 2 & 3 & 4 & 5 \\
\hline Q9 & $0 \%$ & $20 \%$ & $31,1 \%$ & $46,7 \%$ & $2,2 \%$ \\
Q10 & $2,2 \%$ & $15,6 \%$ & $33,3 \%$ & $44,4 \%$ & $4,4 \%$ \\
Q11 & $8,9 \%$ & $20 \%$ & $31,1 \%$ & $37,8 \%$ & $2,2 \%$ \\
AVG & $3,7 \%$ & $18,53 \%$ & $31,83 \%$ & $42,96 \%$ & $2,93 \%$
\end{tabular}

Lebih dari setengah jumlah responden memilih jawaban 34 pada kategori pertanyaan memorability. Sekitar 2,93\% dari jumlah respoden memilih jawaban 5, dan sisanya sebesar $22,23 \%$ memilih jawaban 1-2. 


\begin{tabular}{|l|l|}
\hline \multicolumn{1}{|c|}{ Indikator } & \multicolumn{1}{|c|}{ Hasil } \\
\hline Easy to Remember & $\begin{array}{l}\text { Responden menyatakan CUKUP bahwa fitur dan } \\
\text { navigasi pada Aplikasi RAKERNAS Badan Pusat } \\
\text { Statistik mudah untuk diingat dengan rata-rata } \\
\text { jawaban 3,28 }\end{array}$ \\
\hline Easy to Reestablish & $\begin{array}{l}\text { CUKUP dengan kemudahan jika mengakses } \\
\text { kembali website ini dalam kurun waktu tertentu } \\
\text { dengan rata-rata jawaban 3,04 }\end{array}$ \\
\end{tabular}

Gambar 5. Analisis Indikator Memorability

Dapat disimpulkan bahwa responden menyatakan CUKUP bahwa desain Aplikasi SAKERNAS Badan Pusat Statistik memenuhi aspek memorability dengan rata-rata jawaban 3,16. D. Errors

Tabel 4.

Analisis Jawaban Errors

\begin{tabular}{lccccc}
\hline \hline & 1 & 2 & 3 & 4 & 5 \\
\hline Q9 & $6,7 \%$ & $33,3 \%$ & $42,2 \%$ & $15,6 \%$ & $2,2 \%$ \\
Q10 & $8,9 \%$ & $42,2 \%$ & $37,8 \%$ & $11,1 \%$ & $0 \%$ \\
Q11 & $4,4 \%$ & $42,2 \%$ & $35,6 \%$ & $17,8 \%$ & $0 \%$ \\
AVG & $6,6 \%$ & $39,23 \%$ & $38,53 \%$ & $14,83 \%$ & $0,7 \%$
\end{tabular}

Berdasarkan jawaban responden pada tabel 4. sebagian besar memilih jawaban 2 dengan persentase sebesar 39,23\%, lalu $45 \%$ lebih memilih jawaban 1 dan 3, lalu 15,53\% untuk jawaban 4 dan 5 .

\begin{tabular}{|c|c|}
\hline Indikator & Hasil \\
\hline $\begin{array}{l}\text { Number of Error } \\
\text { Detected }\end{array}$ & $\begin{array}{l}\text { Responden menyatakan CUKUP dengan adanya } \\
\text { error atau kesalahan dalam mengakses Aplikasi } \\
\text { RAKERNAS Badan Pusat Statistik dengan rata-rata } \\
\text { jawaban } \mathbf{2 , 6 2}\end{array}$ \\
\hline Easy to Fix & $\begin{array}{l}\text { Responden CUKUP dengan kesulitan untuk } \\
\text { memperbaiki kesalahan yang dilakukan saat } \\
\text { mengakses website dengan rata-rata jawaban } \mathbf{2 , 6}\end{array}$ \\
\hline
\end{tabular}

Gambar 6. Analisis Indikator Errors

Dapat disimpulkan bahwa responden CUKUP dalam penilaian terkait jumlah errors yang terdeteksi dah kesulitan dalam memperbaiki kesalahan yang terjadi dengan rata-rata jawaban 2,64. dapat disimpulkan bahwa responden CUKUP dalam
E. Satisfaction

Tabel 5.

Analisis Jawaban Satisfaction

\begin{tabular}{lccccc}
\hline \hline & 1 & 2 & 3 & 4 & 5 \\
\hline Q15 & $0 \%$ & $22,2 \%$ & $40 \%$ & $35,6 \%$ & $2,2 \%$ \\
Q16 & $2,2 \%$ & $8,9 \%$ & $35,6 \%$ & $44,4 \%$ & $8,9 \%$ \\
Q17 & $2,2 \%$ & $13,3 \%$ & $33,3 \%$ & $37,8 \%$ & $13.3 \%$ \\
Q18 & $2,2 \%$ & $17,8 \%$ & $31,1 \%$ & $44,4 \%$ & $4,4 \%$ \\
AVG & $1.65 \%$ & $15.55 \%$ & $35 \%$ & $40.55 \%$ & $12.2 \%$
\end{tabular}

Hasil jawaban kuesioner pada tabel 5. adalah aspek Satisfaction, 17,2\% dari total responden memilih jawaban 1-2, $35 \%$ memlih untuk menjawab 3, dan 52,75\% untuk jawaban 4 dan 5 .

\begin{tabular}{|l|l|}
\hline \multicolumn{1}{|c|}{ Indikator } & \multicolumn{1}{|c|}{ Hasil } \\
\hline System Pleasant to & Responden menyatakan CUKUP dengan kesan baik \\
& $\begin{array}{l}\text { yang dihasilkan oleh desain Aplikasi RAKERNAS } \\
\text { Badan Pusat Statistik terbaru dengan rata-rata } \\
\text { jawaban 3,33 }\end{array}$ \\
\hline Comfort to Use & $\begin{array}{l}\text { Responden menyatakan CUKUP dengan } \\
\text { kenyamanan dalam mengakses desain Aplikasi } \\
\end{array}$ \\
& RAKERNAS Badan Pusat Statistik terbaru dengan \\
& rata-rata jawaban 3,38 \\
\hline
\end{tabular}

Gambar 7. Analisis Indikator Satisfaction

Berdasarkan hasil di atas, maka responden CUKUP dengan Aplikasi SAKERNAS Badan Pusat Statistik memenuhi aspek satisfaction atau kepuasan pengguna dengan rata-rata jawaban 3,36 .

\section{PENUTUP}

Beberapa kesimpulan yang dapat diambil pada penelitian ini: A. Hasil Analisa Kuesioner Nielsen Attributtes Of Usability (NAU) pada Aplikasi SAKERNAS PANEL BPS dalam 5 kategori usability seperti Learnability, Efficiency, Memorability, Error, dan Satisfaction menghasilkan hasil CUKUP memenuhi kelima kategori usability menurut Nielsen Model, dengan penilaian CUKUP di 5 parameter.

B. Dari hasil analisis dengan menggunakan metode Nielsen Attributtes Of Usability dari studi kasus yang dilakukan pada Aplikasi SAKERNAS PANEL BPS menunjukan bahwa tingkat sistem usability secara keseluruhan adalah baik dan dapat diterima oleh pengguna.

C. Analisis sistem merupakan usaha dalam memperbaiki usability sistem. Hal ini bermanfaat agar sistem menjadi mudah digunakan dan meningkatkan kepuasan pengguna.

\section{REFERENSI}

[1] E. A. Sosiawan, "Evaluasi implementasi e-government pada situs web pemerintah daerah di Indonesia: Prespektif content dan manajemen," in Seminar Nasional Informatika (SEMNASIF), 2015, vol. 1, no. 5.

[2] S. M. Berliana And L. A. Purbasari, "Faktor-Faktor Yang Memengaruhi Jam Kerja Tenaga Kerja Wanita Berstatus Kawin Dalam Seminggu Di

http://journal.uinjkt.ac.id/index.php/aism 
Indonesia (Analisis Data Sakernas 2014)," vol. 4, no. 3, 2018.

[3] h. Barat, "Badan Pusat Statistik," 2017.

[4] S. X. Dong, "Consistency between Sakernas and the IFLS for analyses of Indonesia's labour market: A cross-validation exercise," vol. 52, no. 3, pp. 343-378, 2016.

[5] S. Lestari, "Analisis Usability Web (Studi Kasus Website Umkm Binaan Bppku Kadin Kota Bandung)," vol. 1, no. 1, 2014.

[6] R. T. Yunandar and P. Priyono, "Pengujian Usability Sistem Framework React Native dengan Expo untuk Pengembangan Aplikasi android Menggunakan USE QUESTIONNAIRE," vol. 3, no. 1, pp. 252-259, 2018.

[7] N. L. A. K. Y. Sarja, "Analisis Pengukuran Faktor Usability Sistem Informasi Konferensi Nasional Sistem Dan Informatika Stikom Bali," vol. 4, no. 1, pp. 1-4-127, 2016.

[8] E. Saputra, Z. Mazalisa, and R. Andriyani, "Usability Testing Untuk Mengukur Penggunaan Website Inspektorat Kota Palembang," 2014.

[9] R. A. Setyawan, W. F. Atapukan, "Pengukuran Usability Website E-
Commerce Sambal Nyoss Menggunakan Metode Skala Likert," vol. 7, no. 1, 2018.

[10] K. R. Hadi, H. M. Az-Zahra, and L. Fanani, "Analisis Dan Perbaikan Usability Aplikasi Mobile KAI Access Dengan Metode Usability Testing Dan Use Questionnaire," vol. 2548, p. 964X, 2018.

[11] S. Möller, "Usability engineering," in Quality Engineering: Springer, 2017, pp. 59-76.

[12] S. Pawirosumarto, "Pengaruh kualitas sistem, kualitas informasi, dan kualitas layanan terhadap kepuasan pengguna sistem e-learning," vol. 6 , no. 3, p. 152864, 2016.

[13] M. Rakhmadian, S. Hidayatullah, and H. Respati, "Analisis Kualitas Sistem Dan Kualitas Informasi Terhadap Kepuasan Pemakai Sistem Informasi Akademik Dosen," in Seminar Nasional Sistem Informasi (SENASIF), 2017, vol. 1, no. 1, pp. 665-675.

[14] K. N. Sigit and E. Soliha, "Kualitas Produk Dan Kualitas Layanan Terhadap Kepuasan Dan Loyalitas Nasabah," vol. 21, no. 1, pp. 157-168, 2017. 
